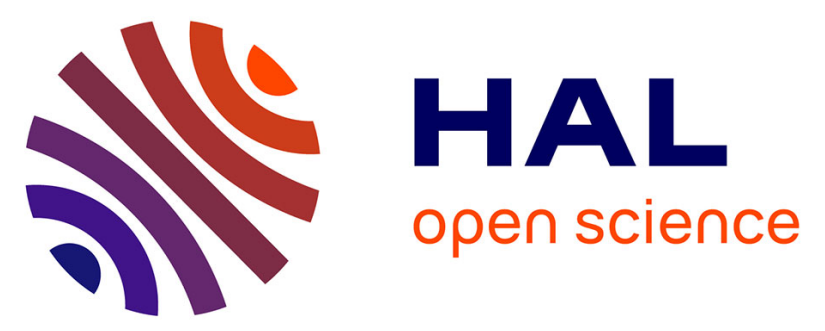

\title{
Planar and Transparent Memristive Devices Based on Titanium Oxide Coated Silver Nanowire Networks with Tunable Switching Voltage
}

Joao Resende, Abderrahime Sekkat, Viet Huong Nguyen, Tomy Chatin, Carmen Jiménez, Mónica Burriel, Daniel Bellet, David Munoz-Rojas

\section{To cite this version:}

Joao Resende, Abderrahime Sekkat, Viet Huong Nguyen, Tomy Chatin, Carmen Jiménez, et al.. Planar and Transparent Memristive Devices Based on Titanium Oxide Coated Silver Nanowire Networks with Tunable Switching Voltage. Small, 2021, 17 (21), pp.2007344. 10.1002/smll.202007344. hal-03286501

\section{HAL Id: hal-03286501 \\ https://hal.univ-grenoble-alpes.fr/hal-03286501}

Submitted on 14 Jul 2021

HAL is a multi-disciplinary open access archive for the deposit and dissemination of scientific research documents, whether they are published or not. The documents may come from teaching and research institutions in France or abroad, or from public or private research centers.
L'archive ouverte pluridisciplinaire HAL, est destinée au dépôt et à la diffusion de documents scientifiques de niveau recherche, publiés ou non, émanant des établissements d'enseignement et de recherche français ou étrangers, des laboratoires publics ou privés. 

Nanowire Networks with Tunable Switching Voltage

\author{
Joao Resende, ${ }^{1,2}$ Abderrahime Sekkat, ${ }^{1}$ Viet Huong Nguyen, ${ }^{3}$ Tomy Chatin, ${ }^{1}$ Carmen \\ Jiménez, ${ }^{1}$ Mónica Burriel, ${ }^{1}$ Daniel Bellet ${ }^{1 *}$, David Muñoz-Rojas ${ }^{1 *}$ \\ ${ }^{1}$ Univ. Grenoble Alpes, CNRS, Grenoble INP, LMGP, F-38000 Grenoble, France \\ ${ }^{2}$ AlmaScience, Campus da Caparica, Almada, Portugal \\ ${ }^{3}$ Faculty of Electrical and Electronic Engineering, Phenikaa University, Hanoi, Vietnam \\ Corresponding authors: daniel.bellet@grenoble-inp.fr and david.munoz- \\ rojas@grenoble-inp.fr
}

Keywords: Resistive Switching, Nanocomposite, $\mathrm{TiO}_{2}, \mathrm{AgNW}$

Threshold Switching devices are fundamental active elements in More than Moore approaches, integrating the new generation of non-volatile memory devices. Here, we report an in-plane threshold resistive switching device with an on/off ratio above $10^{6}$, a Low Resistance State of 10 to $100 \mathrm{k} \Omega$ and a High Resistance State of 10 to $100 \mathrm{G} \Omega$. Our devices are based on nanocomposites of silver nanowire networks and titanium oxide, where volatile unipolar threshold switching takes place across the gap left by partially spheroidized nanowires. Device reversibility depends on the titanium oxide thickness, while nanowire network density determines the threshold voltage, which can reach as low as $0.16 \mathrm{~V}$. The switching mechanism is explained through percolation between metal-semiconductor islands, in a combined tunneling conduction mechanism, followed by a Schottky emission generated via Joule heating. The devices are prepared by low-cost, atmospheric pressure, and scalable techniques, enabling their application in printable, flexible and transparent electronics.

\title{
1. Introduction
}

The interest by the microelectronics industry to evolve from charge storage to resistance change devices has boosted the research activities in resistive switching (RS), both in terms of materials and on possible device structures ${ }^{[1-3]}$. A resistive switching component or memristive device presents a variable resistance that can be controlled by applying a current or voltage ${ }^{[1,4]}$. In the case of threshold switching (TS), the resistance change is volatile, as one of the resistance states is only maintained while the electrical stimulus is preserved ${ }^{[1]}$. These TS components are 


\section{WILEY-VCH}

fundamental as selectors to avoid the propagation of leakage current in non-volatile memory devices $^{[1]}$ and for applications in neuromorphic computation systems ${ }^{[5]}$. Research in resistive switching has been further intensified to create transparent and even flexible devices, in order to produce fully integrated transparent circuits compatible with roll-to-roll technologies and printed electronics ${ }^{[6]}$.

The combination of metallic nanowire networks with oxide thin films has been quite successful in the creation of stable transparent and flexible electrodes for many different applications, such as transparent heaters ${ }^{[7,8]}$, photovoltaics ${ }^{[9]}$, efficient lighting ${ }^{[10]}$ or smart windows ${ }^{[11]}$. Different metallic networks based on silver nanowires (AgNWs) have also been applied in memristive devices in both planar $^{[12-17]}$ and vertical configurations ${ }^{[18-20]}$. These nanowire-based devices present two different switching mechanisms: conductive filament formation and tunneling mechanism. Concerning the first mechanism, Du et al. ${ }^{[15]}$ showed TS of silver@AgO core-shell nanowire networks under an applied voltage . Conductive filaments are created at the junctions between nanowires thanks to the migration of silver atoms from the Ag core through the AgO shell. A TS mechanism was proposed by Yeom et al. ${ }^{[18]}$, where a vertical $\mathrm{Ag}$ filament is formed between a $\mathrm{AgNW}$ s bottom electrode and a platinum top electrode, using titanium dioxide $\left(\mathrm{TiO}_{2}\right)$ both as an insulator and TS medium. In both studies, Joule heating is claimed as the cause of the transition from the Low Resistance State (LRS) to the High Resistance State (HRS) at close to zero bias. However, the formed filaments would remain upon cooling (i.e. reduction in the applied voltage), therefore preserving the LRS. Wan et al. ${ }^{[19]}$ have proposed an alternative mechanism to create a TS device based on the controlled fragmentation of AgNWs in devices fabricated using top contacts. In this case, the conduction through isolated fragments of the network is possible due to tunneling between closely spaced silver nanoparticles (AgNPs) between the nanowires and the top contacts, as reported also by Sun et al. ${ }^{[21]}$. In this mechanism, the existence of a potential barrier between the nanoparticles accounts for both the transition from the LRS to the HRS at low voltages and the volatile nature of the switching.

In our group, the fragmentation and consequent spheroidization of silver nanowires have been intensively studied during stability tests of electrodes under thermal ${ }^{[22,23]}$ and electrical stress $^{[24,25]}$. Importantly, we found that when subjected to a voltage ramp, the resulting network breakdown is a highly correlated and spatially localized phenomenon, where the silver nanowires spheroidize into nanoparticles in a small (i.e. microns) longitudinal region parallel to the electrodes ${ }^{[24]}$. After such a degradation of the network, new conductive pathways can 


\section{WILEY-VCH}

appear when an electrical potential is reapplied ${ }^{[24]}$. The creation of this conductive state between the electrodes yields networks that are two orders of magnitude more resistive than the pristine ones $^{[24]}$. This phenomenon is not yet fully understood and it was proposed to be related to the diffusion of silver atoms ${ }^{[24]}$, as the conduction pathways between the metallic nanoparticles are discrete and localized in specific regions where the nanowires spheroidized.

In this study, we further explored this phenomenon and tuned the electrical breakdown of AgNW networks coated with a $\mathrm{TiO}_{2}$ thin film to create memristive devices based on threshold switching. We report the effect of both network density and oxide coating thickness on the TS phenomenon, and propose a switching mechanism based on a combination of electron tunneling and Schottky emission along conductive paths made of bare and coated silver nanoparticles. The innovative transparent nanocomposite structure deposited on a glass substrate is based on localized degradation of nanowire networks, which enables planar and miniaturized TS devices as no top electrode is required. In addition, we use a combination of low-cost, low-temperature $\left(<150{ }^{\circ} \mathrm{C}\right)$ and scalable technologies, i.e., airbrush spray and atmospheric-pressure spatial atomic layer deposition (AP-SALD) ${ }^{[26]}$, to fabricate the $\mathrm{AgNW} / \mathrm{TiO}_{2}$ nanocomposites, which makes such devices appealing for flexible electronic applications.

\section{Results}

The different steps for the fabrication of the $\mathrm{AgNWs} / \mathrm{TiO}_{2}$ nanocomposites and the subsequent electrical stress test are represented in Figure 1a, as well as a picture of the asfabricated sample in Figure 1b. Further information is developed in the Experimental Section. The resistance of pristine randomly oriented AgNW networks, measured by 2 probes at the edges of the $5 \mathrm{~mm}$ wide samples, varies from 40 to $7 \Omega$ for a corresponding areal mass density (amd) variation from $73 \mathrm{mg} / \mathrm{m}^{2}$ to $110 \mathrm{mg} / \mathrm{m}^{2}$. A SEM micrograph of the silver nanowire networks with an amd of $80 \mathrm{mg} / \mathrm{m}^{2}$ is presented in Figure 1c. The increase in the thickness of the $\mathrm{TiO}_{2}$ thin films from 5 to $45 \mathrm{~nm}$ caused a resistance increase, reaching $100 \Omega$ for a $45 \mathrm{~nm}$ thick $\mathrm{TiO}_{2}$ layer and a $73 \mathrm{mg} / \mathrm{m}^{2}$ areal mass density of the network. A $10 \mathrm{~nm}$ thick $\mathrm{TiO}_{2}$ coating can be observed in the TEM image shown in Figure 1d. The TEM diffraction patterns (Figure S1 in Supplementary Information) confirm the FCC crystalline silver structure of the AgNWs and the amorphous nature of the $\mathrm{TiO}_{2}$ films, as previously reported for thin films deposited below $200{ }^{\circ} \mathrm{C}$ using an AP-SALD system ${ }^{[27,28]}$. The $\mathrm{AgNWs} / \mathrm{TiO}_{2}$ nanocomposite showed an average transmittance of $67 \%$ in the visible range $(390-700 \mathrm{~nm})$, against $87 \%$ for the bare AgNW sample. This variation in transmittance is mainly attributed to the reflection losses due to the thin $\mathrm{TiO}_{2}$ layer (Figure S2 in Supplementary Information). 


\section{WILEY-VCH}

Figure 1e shows the evolution of the resistance for bare and coated networks when subjected to a voltage ramp-up to $15 \mathrm{~V}$. The network densities were 73 and $80 \mathrm{mg} / \mathrm{m}^{2}$ for the bare nanowire network and for the $\mathrm{AgNWs} / \mathrm{TiO}_{2}$ nanocomposite, respectively, where the oxide layer had a thickness of $10 \mathrm{~nm}$. As expected, the presence of $\mathrm{TiO}_{2}$ led to a slight increase in resistance from $14.3 \Omega$ for the bare AgNW network to $42.1 \Omega$ for the nanocomposite. As the electrical stress increased during the voltage ramp, a slight increase in resistance was observed for both samples due to a temperature increase caused by Joule effect ${ }^{[24]}$. At around $12.2 \mathrm{~V}$, the resistance of the electrodes increased sharply due to the formation of a "network-crack", leading to a loss of electrical percolation ${ }^{[24]}$. The crack is the result of a local spheroidization of the nanowires caused by statistical fluctuations in the network density or the amount of junctions, i.e. fluctuations of the resistance within the network. This creates hot spots in the network, where local temperature can reach above $200{ }^{\circ} \mathrm{C}^{[25]}$, leading to the formation of silver nanoparticles with a large dispersion in diameter, from a few nanometers to hundreds nanometers. The detailed mechanism of such a crack formation has been studied and reported previously ${ }^{[24,25]}$. Conversely to the stabilizing effect observed for previously reported nanocomposites made with $\mathrm{ZnO}^{[29,30]}, \mathrm{ZnO}: \mathrm{Al}^{[31]}, \mathrm{ZnO} / \mathrm{Al}_{2} \mathrm{O}_{3}{ }^{[32]}$, in these experiments both bare AgNW and nanocomposite samples underwent a degradation at rather similar voltage values, although with a lower peak resistance for the coated samples.

Nevertheless, in Figure 1e, we can observe that after the formation of the network crack, the resistance decreases above $12 \mathrm{~V}$ and current flows through the electrode again while voltage is still applied, between 13 and $15 \mathrm{~V}$. Such "life-after-crack" phenomenon, where a conductive state with a resistance around $1 \mathrm{k} \Omega$ is observed in both bare and oxide covered samples, has already been reported in our previous studies. ${ }^{[24]}$ Upon application of voltage, current can thus still flow through the crack, generating an average local temperature increase to $40{ }^{\circ} \mathrm{C}$ at $15 \mathrm{~V}$, as shown in the IR image presented in the inset of Figure 1e.

After this initial crack formation, a successive voltage ramp to $10 \mathrm{~V}$ was performed (first half I-V cycle), resulting in the formation of a conductive state, observed for both samples, as put in evidence by the current values above $0.1 \mathrm{~mA}$ reached at $10 \mathrm{~V}$, represented in Figure 2a,b. Thus the samples undergo a resistance switching from a HRS just after the crack formation to a LRS when a voltage ramp is performed. The HRS is characterized by current values below $10 \mathrm{pA}$ at applied voltages close to zero bias, corresponding to a resistance above $10 \mathrm{G} \Omega$. At the end of the first half cycle, new percolating paths are created, similar to a forming cycle, resulting in a LRS at $10 \mathrm{~V}$ with resistance values of $2 \mathrm{k} \Omega$ and $200 \mathrm{k} \Omega$, for the bare AgNWs and the 


\section{WILEY-VCH}

nanocomposite. These conductive states are characterized by high current values above $50 \mu \mathrm{A}$, even if the resistance values are higher than for pristine samples. This LRS obtain has a higher resistance than the one obtained after the initial crack formation Figure 1e at $15 \mathrm{~V}$. This is due to the different voltage bias applied, as well as the different voltage rate.

The samples were then subjected to a series of negative and positive voltage ramps (from $10 \mathrm{~V}$ to $-10 \mathrm{~V}$ and $-10 \mathrm{~V}$ to $10 \mathrm{~V}$, respectively). The bare nanowire networks did not show any switching behavior, shown in Figure 2a, as the network maintains a conductive state with a resistance above $1 \mathrm{k} \Omega$. Conversely, for the $\mathrm{AgNWs} / \mathrm{TiO}_{2}$ nanocomposite, the application of two cycles resulted in the I-V curves shown in Figure 2b, which are typical of a resistive switching behavior. The nanocomposite network thus showed a TS behavior with two well-defined resistance states, LRS and HRS, occurring during each cycle, with resistance values of around $100 \mathrm{k} \Omega$ and 10-100 G $\Omega$, respectively. Furthermore, a difference in the switching voltage was observed between the transition to LRS and HRS. Indeed, in Figure $2 \mathbf{b}$ starting from zero bias at HRS (1), the transition to LRS occurs at a certain threshold voltage, $\mathrm{V}_{\text {th }}$, above $2.5 \mathrm{~V}$ (2), and this conductive state is maintained until $10 \mathrm{~V}$ (3). While reducing the applied voltage from 10 $\mathrm{V}$, the sample switches from LRS to HRS just before the change in polarization, i.e. close to 0 $\mathrm{V}$ (4). The same behavior was observed for the negative sense, with an opposite sign. For the four cycles represented in Figure $2 \mathbf{b}$, a $\mathrm{V}_{\text {th }}$ of $3.7+/-0.5 \mathrm{~V}$ with an $\mathrm{I}_{\mathrm{LRS}} / \mathrm{I}_{\mathrm{HRS}}$ ratio of $2.6 \times 10^{6}$ is observed.

To understand the threshold switching behavior observed in the nanocomposite after generating a network disruption, we studied the influence of the thickness of the $\mathrm{TiO}_{2}$ layer and the density of the AgNW network on the switching phenomena. The results obtained are summarized in Figure 3. Concerning the $\mathrm{TiO}_{2}$ thickness $(5,15$, and $45 \mathrm{~nm})$, we observe the presence of three different behaviors: i) an extremely thin-film of around $5 \mathrm{~nm}$ (Figure 3a) leads to an unstable TS phenomenon, with a high variability of threshold voltage or even the absence on the LRS to HRS transition, similar to what it is observed in bare AgNW networks. ii) $\mathrm{A} \mathrm{TiO}_{2}$ thickness of 10 to $15 \mathrm{~nm}$ allows the formation of LRS and HRS states (Figure $\mathbf{2 b}$ and Figure $\mathbf{3 b}$ and $\mathbf{c}$ ). In these cases, the variation of the threshold voltage with $\mathrm{TiO}_{2}$ thickness is significant: $3.7 \pm 0.5 \mathrm{~V}$ for $10 \mathrm{~nm}$ and $5.2 \pm 1 \mathrm{~V}$ for $15 \mathrm{~nm}$ with similar amd values of 73 $\mathrm{mg} / \mathrm{m}^{2}$. iii) For oxide thickness of around $45 \mathrm{~nm}$, the TS phenomenon is lost and the obtained I-V curve corresponds to a Schottky junction, without any sudden reduction or increase of the current, visible in Figure 3d. Therefore, there is an ideal $\mathrm{TiO}_{2}$ thickness range that yields the 


\section{WILEY-VCH}

TS behavior in this type of memristor devices, corresponding to a $\mathrm{TiO}_{2}$ thickness between 10 and $15 \mathrm{~nm}$ in our case.

The effect of network density on the switching is presented in Figure $\mathbf{3 b}$ and $\mathbf{c}$, where nanocomposites made with networks having amd values of $73 \mathrm{mg} / \mathrm{m}^{2}$ and $109 \mathrm{mg} / \mathrm{m}^{2}$ coated with a $15 \mathrm{~nm}$ thick $\mathrm{TiO}_{2}$ film present different threshold voltages of $5.2 \pm 1 \mathrm{~V}$ and $0.16 \pm 0.03$ $\mathrm{V}$, respectively. The corresponding $\mathrm{I}_{\mathrm{LRS}} / \mathrm{I}_{\mathrm{HRS}}$ ratios were $3.7 \times 10^{6}$ and $8.2 \times 10^{6}$. The lower initial resistance of the denser networks (13.7 $\Omega$ ), when compared to the sparse networks (30.8 $\Omega$ ), could explain the reduction of the threshold voltage, as well as favoring a higher reproducibility in the TS transitions, similar to other devices based on nanowire networks ${ }^{[33]}$. Similarly, the localized crack area contributes to the extremely low threshold voltages obtained. Moreover, these results are reproducible, as shown in Figure S3 of Supporting Information, which presents further IV curves for the different nanocomposite devices, showing similar behavior to the ones in Figure 2 and Figure 3.

The morphological and compositional analyses of the nanocomposites obtained by SEM are fundamental to understand the changes of the $\mathrm{AgNWs} / \mathrm{TiO}_{2}$ network in the crack region, responsible for the TS behavior. These results are presented for bare networks and for nanocomposites made with $\mathrm{TiO}_{2}$ layers (15 and $45 \mathrm{~nm}$ thick) in Figure $\mathbf{4 a}, \mathbf{b}$ and $\mathbf{c}$. The images show an overall view of the region containing the localized crack (on the left), and a magnified view of the damaged region (on the right). The difference in contrast observed in these secondary electrons SEM images is due to the charge effect induced by different conduction between the pristine nanowires with low resistance, and the high resistance of the AgNW and $\mathrm{TiO}_{2}$ composite in the crack region. The crack region is limited to a width of around $20 \mu \mathrm{m}$, spanning through the whole $5 \mathrm{~mm}$ length of the sample, visible in both Figure 4a and $\mathbf{b}$, while the non-damaged nanowires are observable on the sides. The contrast is less visible in the 45 nm thickness $\mathrm{TiO}_{2}$ case in Figure 4c. When observing in detail the crack region of the bare AgNWs, we see that the AgNWs are degraded, leading to the appearance of large silver particles recognized by a higher brightness in the image. A closer view on the $\mathrm{AgNWs} / \mathrm{TiO}_{2}$ nanocomposite allows identifying the $\mathrm{TiO}_{2}$ coating still present around the silver nanowires that endured the electrical breakdown (Figure $\mathbf{4 b}$ and $\mathbf{c}$ ). In Figure S4 of Supporting Information, an EDS mapping of Ti and Ag is presented, showing a Ti presence homogeneously throughout the sample, while Ag was mainly detected on the pristine nanowires out of the crack region and in round particles in the crack region. Two kinds of grains are observed in these images: bright and large ones, which correspond to spherical silver nanoparticles aligned along the path of the 


\section{WILEY-VCH}

previously existing nanowire; the other grains are dark and small, corresponding to $\mathrm{TiO}_{2}$ nanoparticles formed from the $\mathrm{TiO}_{2}$ thin film on the substrate. It was not possible to determine whether these $\mathrm{TiO}_{2}$ nanoparticles are still amorphous or have crystallized due to the heat produced during the formation of the crack. Finally, for a $\mathrm{TiO}_{2}$ thickness to $45 \mathrm{~nm}$ the degradation of the AgNW network is clearly reduced when compared to the previous examples. In this case, we assume that the presence of a thicker $\mathrm{TiO}_{2}$ oxide layer contributes as a conductive medium for current passage, justified by the Schottky behavior of Figure 3d, while at the same time limits the morphological changes in the silver nanowires, as visible in the crack region in Figure 4c.

\section{Discussion and Threshold Switching Model}

Previous studies have shown that the deposition of a thin oxide coating on AgNW networks provides thermal and electrical stabilization of the same thanks to hindered $\mathrm{Ag}$ diffusion through the oxide layer ${ }^{[30]}$. In Table 1, we present the performance of different threshold switching devices based on silver nanowires reported in the literature, comparing the medium, structure, On/Off ratio, and threshold voltage. As shown in the table, our devices show the best performance among the reported planar devices based on AgNWs.

\begin{tabular}{|c|c|c|c|c|}
\hline $\begin{array}{l}\text { Threshold Switching } \\
\text { medium }\end{array}$ & Structure & On/Off ratio & $\mathrm{V}_{\text {th }}(\mathrm{V})$ & Ref \\
\hline $\mathrm{AgNW} / \mathrm{TiO}_{2}$ core-shell & Single nanowire & $10^{7}$ & $0.4-0.6$ & Manning et al., $2017^{[34]}$ \\
\hline $\mathrm{AgNW} / \mathrm{AgO}_{\mathrm{x}}$ core-shell & Planar & 100 & $\sim 0.1-3$ & Du et al., $2017^{[15]}$ \\
\hline $\mathrm{PI} / \mathrm{AgNWs} / \mathrm{TiO}_{2} / \mathrm{Pt}$ & Vertical & 200 & 1.1 & Yeom et al., $2017^{[18]}$ \\
\hline $\mathrm{AgNWs} / \mathrm{AgO}_{\mathrm{x}} / \mathrm{AgNWs}$ & Planar & $5 \times 10^{5}$ & $0.5-20$ & Wan et al., $2018^{[19]}$ \\
\hline $\mathrm{AgNW}$ and $\mathrm{TiO}_{2} \mathrm{NPs}$ & Planar & - & $>100$ & Li et al., $2020^{[17]}$ \\
\hline $\mathrm{AgNWs} / \mathrm{TiO}_{2}$ core-shell & Vertical & $10^{6}$ & 0.1 & Kim et al., $2020^{[35]}$ \\
\hline $\mathrm{AgNWs} / \mathrm{TiO}_{2}$ & Planar & $10^{6}$ & $0.16-5.2$ & This work \\
\hline
\end{tabular}

Conversely, the $\mathrm{AgNW} / \mathrm{TiO}_{2}$ nanocomposites studied here undergo localized degradation at similar voltages than bare AgNW networks, through the formation of a crack upon application of an electrical stress in the form of a voltage ramp. As a result, three different types of structures can be observed within the crack: elongated $\mathrm{AgNW}$ s nanoparticles coated by $\mathrm{TiO}_{2}$, round bare $\mathrm{Ag}$ nanoparticles (i.e. outside the $\mathrm{TiO}_{2}$ shell), and $\mathrm{TiO}_{2}$ nanoparticles having a 
diameter below $10 \mathrm{~nm}$. The formation of these nanostructures within the crack generates a localized region of $20 \mu \mathrm{m}$ that presents volatile unipolar TS behavior, as it is independent on the voltage polarity and only one HRS is observed at close to zero bias. Still, the nanocomposites presented here would require further processing, such as the deposition of an encapsulation layer, in order to ensure a stable TS performance of the $\mathrm{Ag}$ and $\mathrm{TiO}_{2}$ nanostructures in the localized crack region.

We observed that the RS only takes place for $\mathrm{TiO}_{2}$ coatings of a certain thickness, 10 to $15 \mathrm{~nm}$ in our case. For bare networks or for networks coated with $\mathrm{TiO}_{2}$ films with thickness below $10 \mathrm{~nm}$, the migration of silver atoms results in electrical conduction pathways, yielding a LRS regardless of the applied voltage, even at applied voltages close to zero bias. In these cases, the RS behavior cannot be tuned with the applied voltage. This observation disagrees with the commonly reported conductive filament mechanism, in which a transition from LRS to HRS would take place due to the filament being disrupted by Joule heating ${ }^{[15],[18]}$. When a $40 \mathrm{~nm}$ thick $\mathrm{TiO}_{2}$ coating is present, the diffusion of silver is hindered and most silver nanoparticles in the crack are still surrounded by a thick layer of insulating $\mathrm{TiO}_{2}$, as can be seen in Figure 4c. This would prevent an ohmic electrical transport, resulting in the formation of a Schottky junction between $\mathrm{TiO}_{2}$ and $\mathrm{Ag}$, as already reported for both silver thin films ${ }^{[36]}$ and nanowires ${ }^{[37]}$. Thus, for intermediate thicknesses of $10-15 \mathrm{~nm}$, the crack region would contain both bare and coated AgNPs in which the coating would be thin enough to allow the pass of current upon application of a voltage (see scheme in Figure 5a). This clearly implies that the $\mathrm{TiO}_{2}$ plays a key role in the switching behavior, both affecting the diffusion of $\mathrm{Ag}$ atoms during the electrical breakdown, and by tuning the electric contact between silver nanoparticles due to the insulating nature of the oxide. These results also imply that the previously proposed mechanism for systems composed of a metal and an oxide thin film purely based on the formation of silver filaments across the $\mathrm{TiO}_{2}$ film ${ }^{[15]}$ does not apply in our case.

In order to gain further insight on the main factors governing the switching mechanism that takes place in our system, we evaluated the relationship between network density and the power needed to induce the switching. The electrical power generated dependence with the applied voltage for different network densities is plotted in Figure 5b. Remarkably, we observed that the threshold switching takes place at similar electrical power values, regardless of the network density used, represented by the color dots in Figure 5b. This fact explains the reduction of the threshold voltage with the increase of the network density, since denser networks present a lower resistance and thus a higher current for a given voltage than sparser 


\section{WILEY-VCH}

networks. It can also be observed that in all cases the electrical power consistently changes from around $1 \mathrm{nW}$ to $100 \mu \mathrm{W}$ upon switching from HRS to LRS. When reversing the voltage ramp, the LRS is in all cases lost when the electrical power is reduced to around $10 \mathrm{pW}$. Figure $\mathbf{5 b}$ also shows the switching cycles for networks coated with different $\mathrm{TiO}_{2}$ thicknesses (10 vs. 15 $\mathrm{nm})$. As can be seen, the thickness of the coating has no direct effect on the power.

The fact that the switching happens in all cases at similar power values would imply that is governed by the heat-induced by the Joule effect. As a consequence, we propose a TS mechanism based on two different phenomena: i) electron tunneling over the physical distance of extremely close silver nanostructures (including coated ones) and ii) conduction through the isolating shell of $\mathrm{TiO}_{2}$ by Schottky emission ${ }^{[38]}$. As the applied voltage increases, starting from zero bias at the HRS, the transition to the LRS occurs at a certain threshold voltage due to an abrupt electron tunneling between close silver nanoparticles and nanowires. As the temperature of the system increases due to Joule heating, thermally-activated electrons can be injected over the energy barrier of the $\mathrm{TiO}_{2}$ conduction band allowing a Schottky emission ${ }^{[38]}$ through the oxide shell. Once Schottky emission starts taking place, it induces a further Joule heating, thus developing a chain reaction process that yields a sharp increase in current. This allows a stable conductive state after the switching until the maximum voltage value of the cycle is reached. When the voltage ramp is reversed, the conductive state is maintained as the Schottky barrier between $\mathrm{TiO}_{2}$ and $\mathrm{Ag}$ is already overcome, i.e. the activated electrons are still mobile. Nevertheless, as the voltage keeps decreasing and reaches values close to zero bias, the conductive state is lost as electrons cannot pass through the potential barrier anymore. This state is created by a decrease in the flow of electrons from $\mathrm{TiO}_{2}$ and $\mathrm{AgNW}$ since the cooling down effect reduces the probability of electrons to overcome the Schottky potential barrier and thus the conduction is lost, reaching the HRS. The combination of electron tunneling and Schottky emission has already been reported in resistive switching devices systems ${ }^{[39,40]}$, nevertheless, the combined mechanisms have never been used to describe a TS device of silver nanowires, to the best of our knowledge. Furthermore, the Schottky emission mechanism is characterized by the following relationship between current, $I$, and voltage, $V$ :

$$
\operatorname{Ln}(I) \propto \frac{q}{k_{b} T} \sqrt{q / 4 \pi \varepsilon_{0} \varepsilon_{r} d} \sqrt{V}
$$

Where $q$ is the charge of electron, $k_{b}$ is the Boltzmann constant, $T$ the temperature considered as $300 \mathrm{~K}, \varepsilon_{0}$ the vacuum permittivity, and $d$ the thickness of the oxide. In Figure 5c, we observe the linear dependence of the logarithm of current with the square of the voltage in the LRS region for three different nanocomposites. The linear relation in the LRS confirms the 


\section{WILEY-VCH}

Schottky emission process, showing a slope between 1.1 and 1.3 for the nanocomposites with a sparse network and a slope of 3.9 for the denser networks. Considering the dielectric constant, $\varepsilon_{\mathrm{r}}$, of amorphous $\mathrm{TiO}_{2}$ reported in the literature, between $13.7^{[41]}$ and $18^{[42]}$, we can estimate the thickness of $\mathrm{TiO}_{2}$ in the Schottky emission process. For sparse networks, the thickness of the $\mathrm{TiO}_{2}$ is estimated to be between 70 and $130 \mathrm{~nm}$. Since a less dense network reduces the amount of highly conductive metallic structures in the TS region, this would result in a higher electron conduction through $\mathrm{TiO}_{2}$. As the amount of nanowires increases for the denser networks, the thickness of the $\mathrm{TiO}_{2}$ involved in the conduction is reduced to between 7 and $10 \mathrm{~nm}$. This is indeed expected, as on average, the oxide contributing to the conduction pathways is diminished since the amount of silver nanostructures as nanowires and round nanoparticles increase. Therefore, the electron path will mostly involve the more conductive silver nanostructures.

\section{Conclusion}

In conclusion, we have demonstrated that nanocomposites of silver nanowire networks and titanium oxide thin films present in-plane threshold switching. Optimized devices have $\mathrm{I}_{\mathrm{LRS}} / \mathrm{I}_{\mathrm{HRS}}$ ratios above $10^{6}$ with threshold voltages as low as $0.16 \mathrm{~V}$. The switching region consists of silver nanoparticles and titanium oxide shells obtained by the spheroidization of the AgNWs/TiO 2 composites having a specific $\mathrm{TiO}_{2}$ thickness, $10-15 \mathrm{~nm}$ in our case. When low voltages are applied, the coated network has a high resistance of $10 \mathrm{G} \Omega$ that drastically changes to a low resistance state of $10 \mathrm{k} \Omega$ above a certain voltage threshold. We also demonstrated that the $\mathrm{V}_{\text {th }}$ value can be drastically reduced from 3.7 to $0.16 \mathrm{~V}$ by increasing the network density. The physical mechanism involved in the switching of our devices is based on an initial conduction through tunneling between close Ag fragments, followed by a Schottky emission across the $\mathrm{TiO}_{2}$ coating, which is generated by the Joule effect caused by the initial tunneling current. This threshold-switching phenomenon in a transparent nanocomposite has a high interest for neuromorphic computation applications as it can be then integrated into new types of devices that can be both transparent and flexible.

\section{Experimental Section}

\section{Silver Nanowire networks and Titanium Oxide Deposition}

The silver nanowires were kindly provided by the research team of Jean-Pierre Simonato from CEA-LETI, France, as detailed in Mayousse et al. ${ }^{[43]}$. In terms of dimensions, the AgNWs present an average diameter of $79 \pm 10 \mathrm{~nm}$ and an average length of $7 \pm 3 \mu \mathrm{m}$, while the 


\section{WILEY-VCH}

deposition solution was prepared with a concentration of $0.1 \mathrm{~g} / \mathrm{L}$ diluted in methanol. As a rigid substrate, an alkaline $25 \times 25 \mathrm{~mm}^{2}$ earth boroaluminosilicate glass (Corning 1737) was used, sonicated during 15 minutes in isopropanol, rinsed with distilled water, and finally dried with $\mathrm{N}_{2}$ gas. The fabrication of the AgNW networks was conducted via spray deposition using a home-made airbrush set-up composed of a spray gun, a robotic arm, and a heating plate. The automated system uses $\mathrm{N}_{2}$ as spraying gas with a pressure of 1.4 bar and the substrates were heated at $110{ }^{\circ} \mathrm{C}$ to easily evaporate the solvent. The network density is controlled by adjusting the number of spray cycles.

The $\mathrm{TiO}_{2}$ films were deposited using a home-made AP-SALD ${ }^{[44]}$ using $\mathrm{TiCl}_{4}$ as titanium precursor and water as oxygen precursor. The deposition was performed at a substrate temperature of $150{ }^{\circ} \mathrm{C}$ and in the open air. The substrate was placed at a short distance, $150 \mu \mathrm{m}$, from the gas injection head, and was oscillated at a speed of $6.5 \mathrm{~cm} / \mathrm{s}$. Our system allows a uniform deposition of $\mathrm{TiO}_{2}$ thin films over an area of $50 \times 50 \mathrm{~mm}^{2}$. The thickness of the $\mathrm{TiO}_{2}$ film was controlled by the number of AP-SALD cycles. The final nanocomposite samples were then cut and divided into $5 \times 5 \mathrm{~mm}^{2}$ specimens. Silver-paste-based contacts were manually deposited at two opposite sides of the specimen and dried for 12 hours in the ambient air. The resulting distance between the two electrodes in each sample was $4.8 \mathrm{~mm}$.

\section{Characterization techniques and electrical measurements}

Scanning Electron Microscopy (SEM) was conducted in a FEI Quanta 250 FE-ESEM tool, with an energy beam of $10 \mathrm{keV}$. The areal mass density, which corresponds to the mass of material per unit surface is measured using SEM micrographs and a plugin of the Software ImageJ. Transmission electron microscopy (TEM) imaging was obtained with a JEOL JEM 2010 microscope operating at $200 \mathrm{kV}$ (0.19 nm resolution), provided with an EDS system, INCA Energy TEM 100 X-Max 65T. The sample preparation for TEM imaging was based on the crushing technique, as the $\mathrm{TiO}_{2}$ coated $\mathrm{AgNW}$ s were removed from the glass substrate using a spatula and then dropped onto the TEM microgrid.

The electrical measurements of the electrode were conducted using a Keithley 2400 source meter using a 2-tip probe station, contacted at the edges of each specimen. The electrical breakdown was performed by a voltage ramp from 0 to $15 \mathrm{~V}$, with a voltage sweep rate of 24 $\mathrm{V} / \mathrm{min}$, similarly, for the first voltage cycle between 0 and $10 \mathrm{~V}$. The threshold bipolar switching cycles were conducted between $10 \mathrm{~V}$ and $-10 \mathrm{~V}$, and back to $10 \mathrm{~V}$, or $0.4 \mathrm{~V}$ to $-0.4 \mathrm{~V}$ and back to $0.4 \mathrm{~V}$, with a voltage rate of $100 \mathrm{~V} / \mathrm{min}$ and $4 \mathrm{~V} / \mathrm{min}$, respectively. 


\section{WILEY-VCH}

\section{Acknowledgments}

This project was supported by the French National Research Agency in the framework of the "Investissements d'avenir" program (ANR-15-IDEX-02) through the project Eco-SESA. This work was also performed within the framework of the Centre of Excellence of Multifunctional Architectured Materials "CEMAM" $n^{\circ}$ AN-10-LABX-44-01. This work was funded by the Agence Nationale de Recherche (ANR, France) via the programs ANR-16-CE050021 (DESPATCH), ANR-14-ACHN-0012 (MICROSWITCH) and CE05 INDEED, CE09 MEANING, CE09 PANASSE. This work was as well supported by Région Auvergne RhôneAlpes through the project Pack Ambition Recherche 2018 Eternité. The Carnot Energies du Futur is acknowledged through the project FREE. David Muñoz-Rojas acknowledges funding through the Marie Curie Actions (FP7/2007-2013, Grant 631111). The authors would like to warmly thank to L. Rapenne, K. Maas and R. Rodríguez-Lamas for fruitful discussions.

Received: ((will be filled in by the editorial staff))

Revised: ((will be filled in by the editorial staff)) Published online: ((will be filled in by the editorial staff))

\section{References}

[1] S. Slesazeck, T. Mikolajick, Nanotechnology 2019, 30, 352003.

[2] J. J. Yang, D. B. Strukov, D. R. Stewart, Nature Nanotechnology 2013, 8, 13.

[3] D. Ielmini, H.-S. P. Wong, Nature Electronics 2018, 1, 333.

[4] J. S. Lee, S. Lee, T. W. Noh, Appl. Phys. Rev. 2015, 2, 031303.

[5] W. Wang, M. Laudato, E. Ambrosi, A. Bricalli, E. Covi, Y.-H. Lin, D. Ielmini, IEEE Trans. Electron Devices 2019, 66, 3802.

[6] J. Yao, J. Lin, Y. Dai, G. Ruan, Z. Yan, L. Li, L. Zhong, D. Natelson, J. M. Tour, Nat Commun 2012, 3, 1101.

[7] S. Sorel, D. Bellet, J. N. Coleman, ACS Nano 2014, 8, 4805.

[8] D. T. Papanastasiou, A. Schultheiss, D. Muñoz-Rojas, C. Celle, A. Carella, J.-P. Simonato, D. Bellet, Advanced Functional Materials 2020, 1910225.

[9] F. Guo, N. Li, V. V. Radmilović, V. R. Radmilović, M. Turbiez, E. Spiecker, K. Forberich, C. J. Brabec, Energy Environ. Sci. 2015, 8, 1690.

[10] S. Coskun, E. Selen Ates, H. Emrah Unalan, Nanotechnology 2013, 24, 125202.

[11] R. Yuksel, E. Ataoglu, J. Turan, E. Alpugan, S. Ozdemir Hacioglu, L. Toppare, A. Cirpan, H. Emrah Unalan, G. Gunbas, Journal of Polymer Science Part A: Polymer Chemistry 2017, 55, 1680.

[12] S. I. White, P. M. Vora, J. M. Kikkawa, J. E. Fischer, K. I. Winey, J. Phys. Chem. C 2010, 114, 22106.

[13] C.-P. Hsiung, H.-W. Liao, J.-Y. Gan, T.-B. Wu, J.-C. Hwang, F. Chen, M.-J. Tsai, ACS Nano 2010, 4, 5414.

[14] S. I. White, P. M. Vora, J. M. Kikkawa, K. I. Winey, Advanced Functional Materials 2011, 21, 233. 


\section{WILEY-VCH}

[15] H. Du, T. Wan, B. Qu, F. Cao, Q. Lin, N. Chen, X. Lin, D. Chu, ACS Applied Materials \& Interfaces 2017, 9, 20762.

[16] A. Diaz-Alvarez, R. Higuchi, P. Sanz-Leon, I. Marcus, Y. Shingaya, A. Z. Stieg, J. K. Gimzewski, Z. Kuncic, T. Nakayama, Sci Rep 2019, 9, 14920.

[17] Q. Li, A. Diaz- Alvarez, R. Iguchi, J. Hochstetter, A. Loeffler, R. Zhu, Y. Shingaya, Z. Kuncic, K. Uchida, T. Nakayama, Adv. Funct. Mater. 2020, 2003679.

[18] S.-W. Yeom, B. You, K. Cho, H. Y. Jung, J. Park, C. Shin, B.-K. Ju, J.-W. Kim, Scientific Reports 2017, 7, DOI 10.1038/s41598-017-03746-1.

[19] T. Wan, Y. Pan, H. Du, B. Qu, J. Yi, D. Chu, ACS Applied Materials \& Interfaces 2018, $10,2716$.

[20] W. Wang, M. Wang, E. Ambrosi, A. Bricalli, M. Laudato, Z. Sun, X. Chen, D. Ielmini, Nat Commun 2019, 10, 81 .

[21] H. Sun, Q. Liu, C. Li, S. Long, H. Lv, C. Bi, Z. Huo, L. Li, M. Liu, Adv. Funct. Mater. 2014, 24, 5679.

[22] D. P. Langley, M. Lagrange, G. Giusti, C. Jiménez, Y. Bréchet, N. D. Nguyen, D. Bellet, Nanoscale 2014, 6, 13535.

[23] M. Lagrange, T. Sannicolo, D. Muñoz-Rojas, B. G. Lohan, A. Khan, M. Anikin, C. Jiménez, F. Bruckert, Y. Bréchet, D Bellet, Nanotechnology 2017, 28, 055709.

[24] T. Sannicolo, N. Charvin, L. Flandin, S. Kraus, D. T. Papanastasiou, C. Celle, J.-P. Simonato, D. Muñoz-Rojas, C. Jiménez, D. Bellet, ACS Nano 2018, 12, 4648.

[25] N. Charvin, J. Resende, D. T. Papanastasiou, D. Muñoz-Rojas, C. Jiménez, A. Nourdine, D. Bellet, L. Flandin, Nanoscale Adv. 2021, 10.1039.D0NA00895H.

[26] D. Muñoz-Rojas, T. Maindron, A. Esteve, F. Piallat, J. C. S. Kools, J.-M. Decams, Materials Today Chemistry 2019, 12, 96.

[27] D. Muñoz-Rojas, H. Sun, D. C. Iza, J. Weickert, L. Chen, H. Wang, L. Schmidt-Mende, J. L. MacManus-Driscoll, Progress in Photovoltaics: Research and Applications 2013, $21,393$.

[28] S. Moitzheim, J. E. Balder, P. Poodt, S. Unnikrishnan, S. De Gendt, P. M. Vereecken, Chem. Mater. 2017, 29, 10007.

[29] W. Lan, Z. Yang, Y. Zhang, Y. Wei, P. Wang, A. Abas, G. Tang, X. Zhang, J. Wang, E. Xie, Applied Surface Science 2018, 433, 821.

[30] A. Khan, V. H. Nguyen, D. Muñoz-Rojas, S. Aghazadehchors, C. Jiménez, N. D. Nguyen, D. Bellet, ACS Applied Materials \& Interfaces 2018, 10, 19208.

[31] V. H. Nguyen, J. Resende, D. T. Papanastasiou, N. Fontanals, C. Jiménez, D. MuñozRojas, D. Bellet, Nanoscale 2019, 11, 12097.

[32] S. Aghazadehchors, V. H. Nguyen, D. Muñoz-Rojas, C. Jiménez, L. Rapenne, N. D. Nguyen, D. Bellet, Nanoscale 2019, 11, 19969.

[33] M. Legallais, T. T. T. Nguyen, T. Cazimajou, M. Mouis, B. Salem, C. Ternon, Materials Chemistry and Physics 2019, 238, 121871.

[34] H. G. Manning, S. Biswas, J. D. Holmes, J. J. Boland, ACS Applied Materials \& Interfaces 2017, 9, 38959.

[35] Y. Kim, W. Jeon, M. Kim, J. H. Park, C. S. Hwang, S.-S. Lee, Applied Materials Today 2020, 19, 100569.

[36] K. K. Paul, P. K. Giri, J. Phys. Chem. C 2017, 121, 20016.

[37] J. Xu, W. Yang, H. Chen, L. Zheng, M. Hu, Y. Li, X. Fang, J. Mater. Chem. C 2018, 6, 3334.

[38] E. Lim, R. Ismail, Electronics 2015, 4, 586.

[39] M. Hansen, M. Ziegler, H. Kohlstedt, in 2016 IEEE International Conference on Rebooting Computing (ICRC), IEEE, San Diego, CA, USA, 2016, pp. 1-8.

[40] D. Y. Guo, Z. P. Wu, L. J. Zhang, T. Yang, Q. R. Hu, M. Lei, P. G. Li, L. H. Li, W. H. Tang, Appl. Phys. Lett. 2015, 107, 032104. 
[41] W. G. Lee, S. I. Woo, J. C. Kim, S. H. Choi, K. H. Oh, Thin Solid Films 1994, 237, 105.

[42] Q. Cheng, W. Ahmad, G. Liu, K. Wang, in 2011 11th IEEE International Conference on Nanotechnology, IEEE, Portland, OR, USA, 2011, pp. 1598-1601.

[43] C. Mayousse, C. Celle, E. Moreau, J.-F. Mainguet, A. Carella, J.-P. Simonato, Nanotechnology 2013, 24, 215501.

[44] V. H. Nguyen, D. Bellet, B. Masenelli, D. Muñoz-Rojas, ACS Applied Nano Materials 2018, $1,6922$.

a

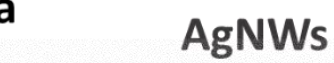

Deposition

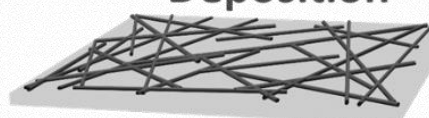

Conductive Network $R=7-40 \Omega$
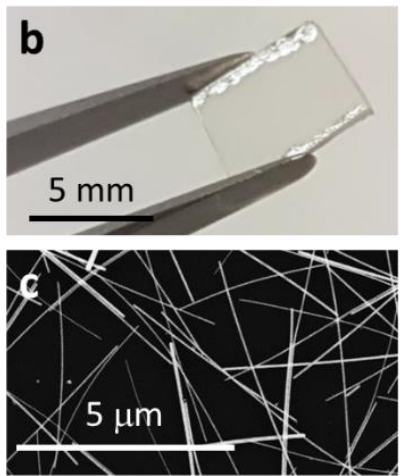

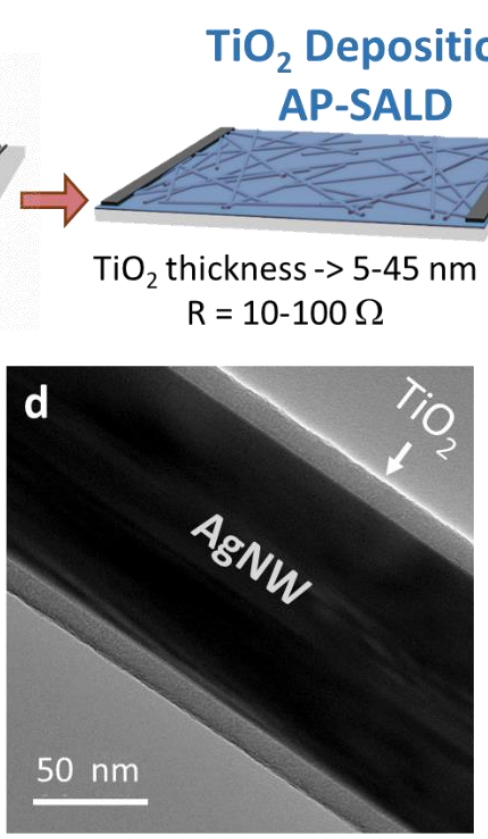

\section{Forming Cycle}

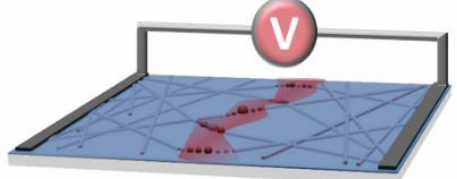

Voltage Ramp from 0 to $15 \mathrm{~V}$ $\mathrm{R}>1 \mathrm{~K} \Omega$ at $15 \mathrm{~V}$

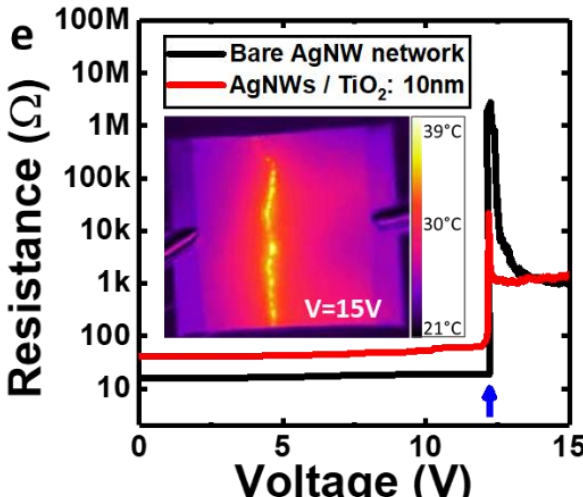

Figure 1. a. Schematic of the in-plane threshold switching device fabrication process: AgNWs deposition by airbrush followed by $\mathrm{TiO}_{2}$ deposition by AP-SALD. The formation of the network crack in red is obtained during an electrical stress test up to $15 \mathrm{~V}$, spanning through the whole sample with a length of $5 \mathrm{~mm}$. b. Photo of the as-fabricated device on glass $\mathbf{c}$. SEM image of an AgNW network with an amd of $80 \mathrm{mg} / \mathrm{m}^{2}$. d. TEM image of a silver nanowire covered with a $10 \mathrm{~nm}$ thick $\mathrm{TiO}_{2}$ coating. e. In situ resistance measurement during an electroforming voltage ramp between 0 and $15 \mathrm{~V}$ for a bare AgNW network, in black, and the $\mathrm{AgNWs} / \mathrm{TiO}_{2}: 10 \mathrm{~nm}$ nanocomposite in red. The blue arrow represents the network breakdown voltage for both samples. Inset of an infrared image of the bare AgNW network for an applied voltage of $15 \mathrm{~V}$ after the electrode breakdown, with vertical electrodes placed on opposite edges of the sample. 

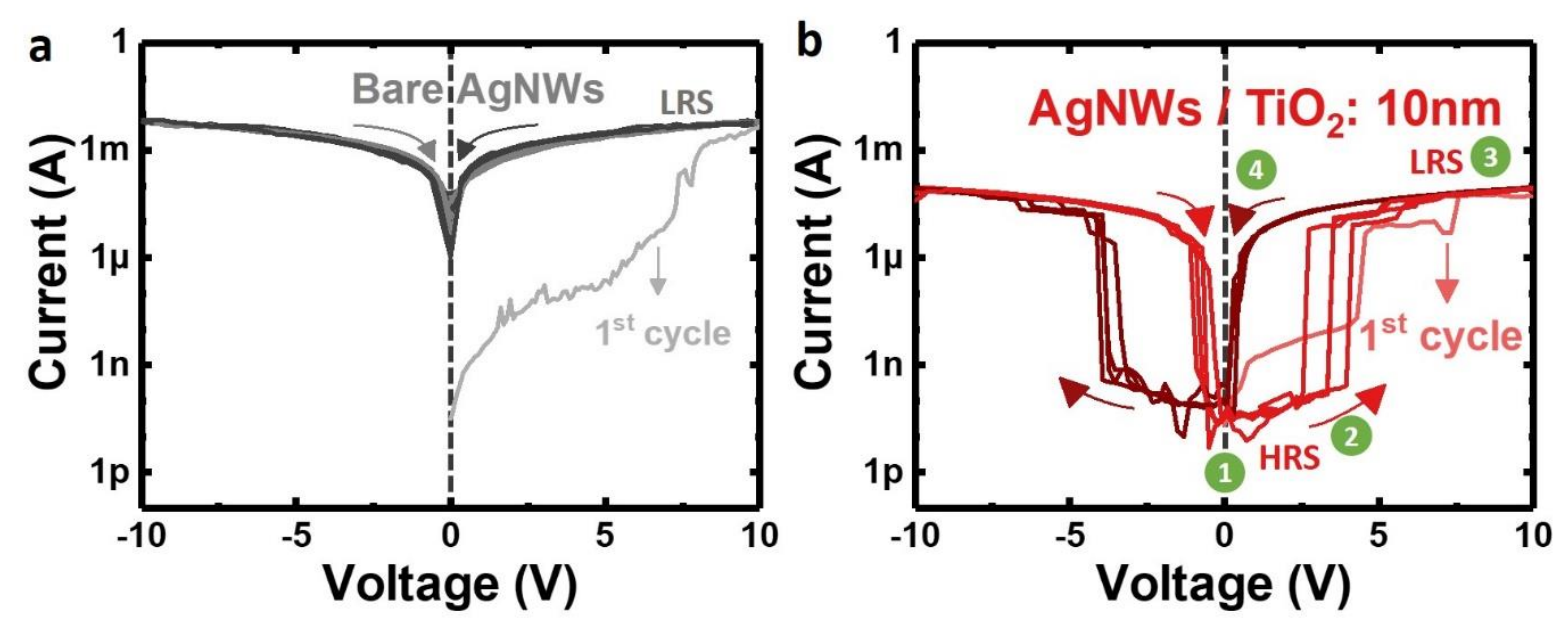

Figure 2. I-V cycles for the a. bare $\mathrm{AgNWs}$ in grey and b. $\mathrm{AgNWs} / \mathrm{TiO}_{2}: 10 \mathrm{~nm}$ nanocomposite in red. Creation of LRS by a 1 st half cycle from 0 to $10 \mathrm{~V}$ for the bare $\mathrm{AgNW}$ network and the nanocomposite shown in light grey and light red, respectively. Current vs. applied voltage during 4 cycles from $-10 \mathrm{~V}$ to $10 \mathrm{~V}$, where the numbers 1 to 4 in b. represent the different current stages on the $\mathrm{AgNWs} / \mathrm{TiO}_{2}$ nanocomposite on a cycle from $0 \mathrm{~V}$ to $10 \mathrm{~V}$ and back to $0 \mathrm{~V}$.
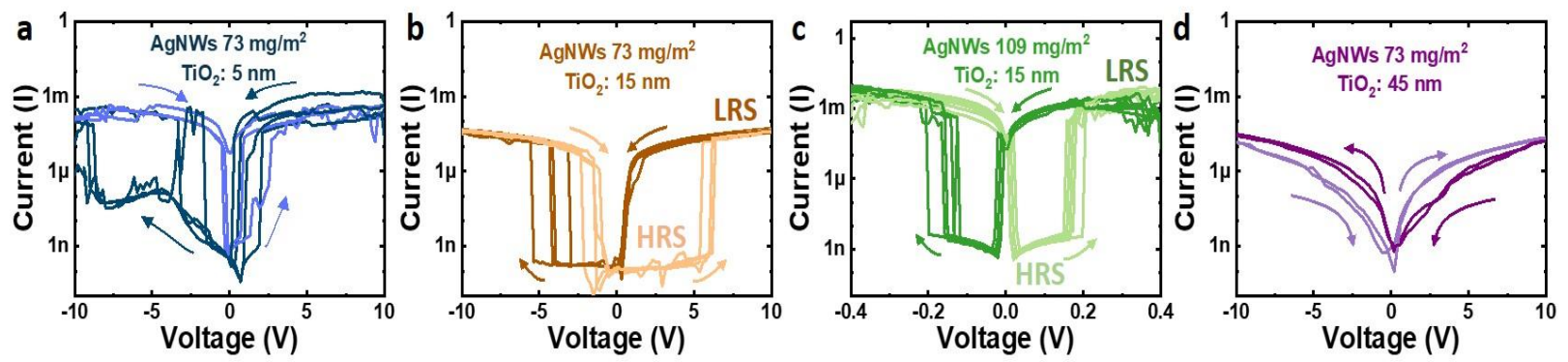

Figure 3. $\mathrm{I}-\mathrm{V}$ curves for $\mathrm{AgNW} / \mathrm{TiO}$ nanocomposites with different $\mathrm{AgNWs}$ amd and $\mathrm{TiO}_{2}$ thickness: a. 4 voltage cycles performed on a $5 \mathrm{~nm} \mathrm{TiO}$ layer nanocomposite (amd $=73 \mathrm{mg} / \mathrm{m}^{2}$ ), b. and c. 4 voltage cycles on a $15 \mathrm{~nm} \mathrm{TiO}_{2}$ layer nanocomposite for (b) sparse network amd = $73 \mathrm{mg} / \mathrm{m}^{2}$ and (c) for dense network $a m d=109 \mathrm{mg} / \mathrm{m}^{2} ; \mathbf{d}$. 2 voltage cycles on a $45 \mathrm{~nm} \mathrm{TiO}_{2}$ layer nanocomposite with $a m d=73 \mathrm{mg} / \mathrm{m}^{2}$. 


\section{WILEY-VCH}
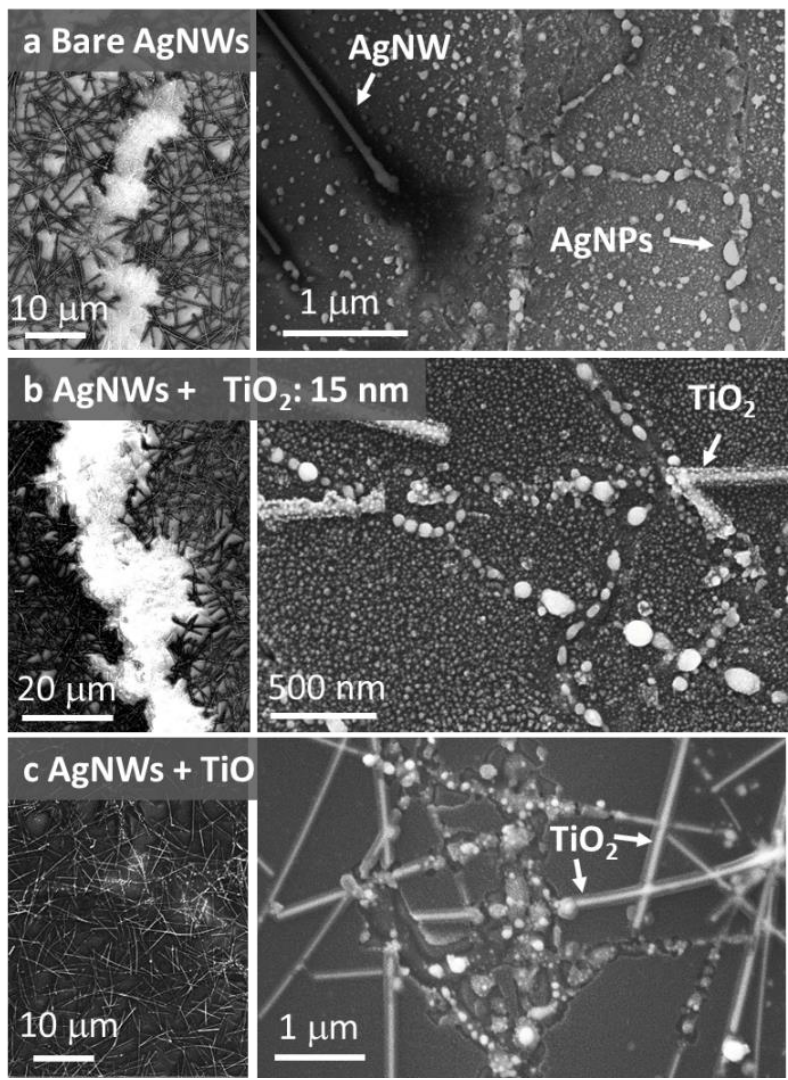

Figure 4. Secondary electron SEM images of the crack region in the AgNW network after threshold switching voltage cycles. a. bare AgNWs, b. AgNWs with a $\mathrm{TiO}_{2}$ coating of $15 \mathrm{~nm}$ and c. AgNWs with a $\mathrm{TiO}_{2}$ coating of $45 \mathrm{~nm}$. General view of the localized crack region (on the left) and a magnified view of the damaged region (on the right).

a

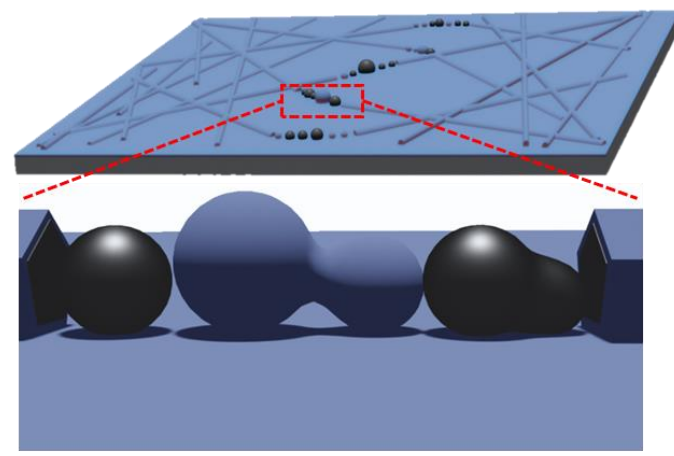

b

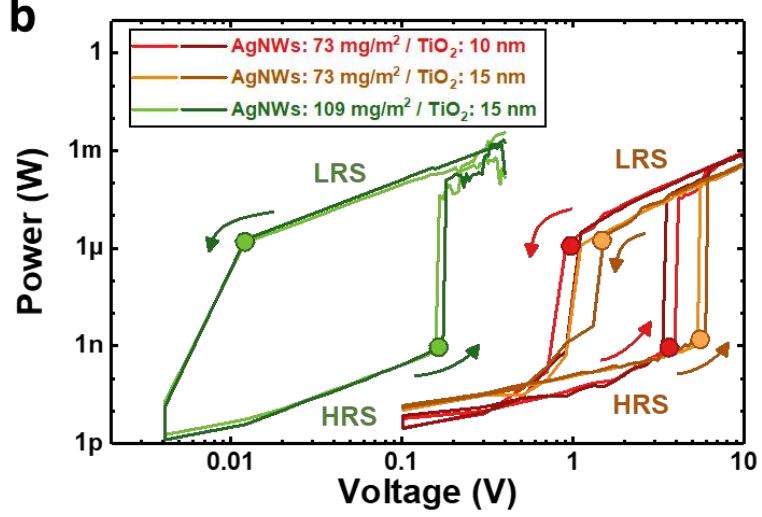

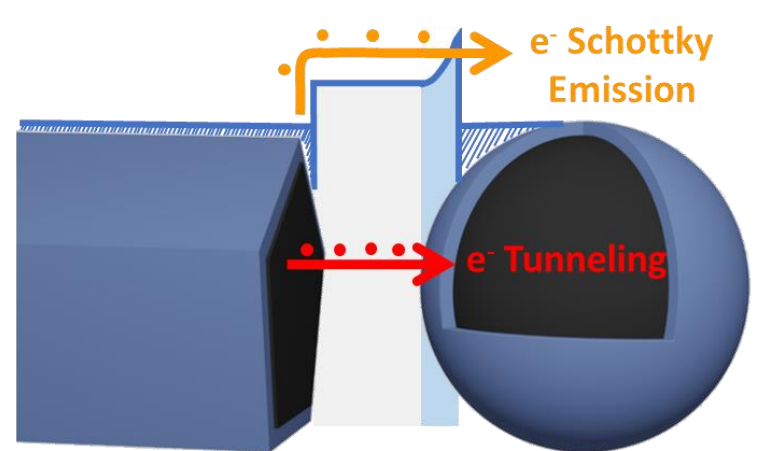

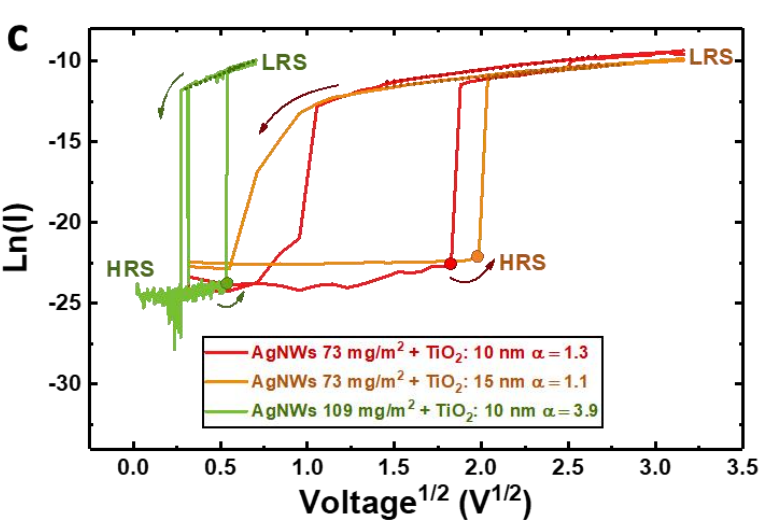




\section{WILEY-VCH}

Figure 5. a. Scheme of the Threshold Switching mechanism with the formation of $\mathrm{Ag}$ nanoparticles between the $\mathrm{AgNWs} / \mathrm{TiO}_{2}$ nanostructures. The gap between particles creates a tunneling potential, while the $\mathrm{TiO}_{2}$ layer acts as an insulating component, creating a Schottky barrier with the Ag particles. b. Power dependence with voltage for three different nanocomposites with variable $\mathrm{AgNW}$ density and $\mathrm{TiO}_{2}$ coating thickness. Red, yellow and green dots represent the voltages where the power abruptly changes, resulting in a resistance state transition. c. Schottky relation with voltage following a $\operatorname{Ln}(\mathrm{I})$ vs $\mathrm{V}^{1 / 2}$ dependence for a cycle for three different $\mathrm{AgNWs} / \mathrm{TiO}_{2}$ nanostructures, with dots representing the transition voltages. $\alpha$ values represent the slope of the different curves in the LRS 


\section{WILEY-VCH}

We demonstrate a transparent resistive switching devices entirely fabricated by open-air approaches, without a deposition chamber. The threshold voltage can be tuned by adjusting the density of AgNWs, while maintaining a high LRS/HRS ratio. We show the effect of oxide thickness on the threshold-switching phenomenon, thus shedding light on the conduction mechanism of these type of switching devices.

Joao Resende, ${ }^{1,2}$ Abderrahime Sekkat, ${ }^{1}$ Viet Huong Nguyen, ${ }^{3}$ Tomy Chatin, ${ }^{1}$ Carmen Jiménez, ${ }^{1}$ Mónica Burriel, ${ }^{1}$ Daniel Bellet ${ }^{1 *}$, David Muñoz-Rojas ${ }^{1 *}$

\section{Planar and Transparent Memristive devices based on Titanium Oxide coated Silver Nanowire Networks with tunable switching voltage}

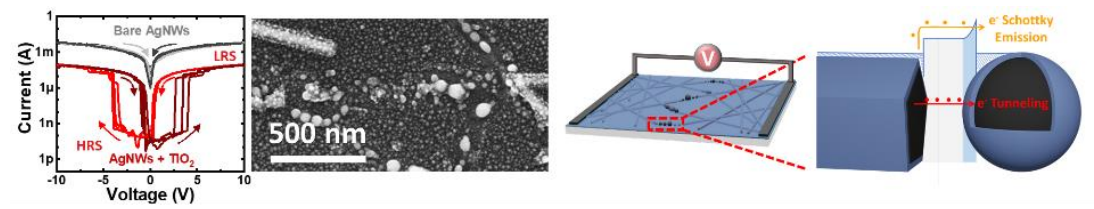




\section{WILEY-VCH}

(c) Copyright 2020. WILEY-VCH GmbH.

\section{Supporting Information}

\section{Planar and Transparent Memristive devices based on Titanium Oxide coated Silver Nanowire Networks with tunable switching voltage}

Joao Resende, ${ }^{1,2}$ Abderrahime Sekkat, ${ }^{1}$ Viet Huong Nguyen, ${ }^{3}$ Tomy Chatin, ${ }^{1}$ Carmen Jiménez, ${ }^{1}$ Mónica Burriel, ${ }^{1}$ Daniel Bellet ${ }^{1 *}$, David Muñoz-Rojas ${ }^{1 *}$
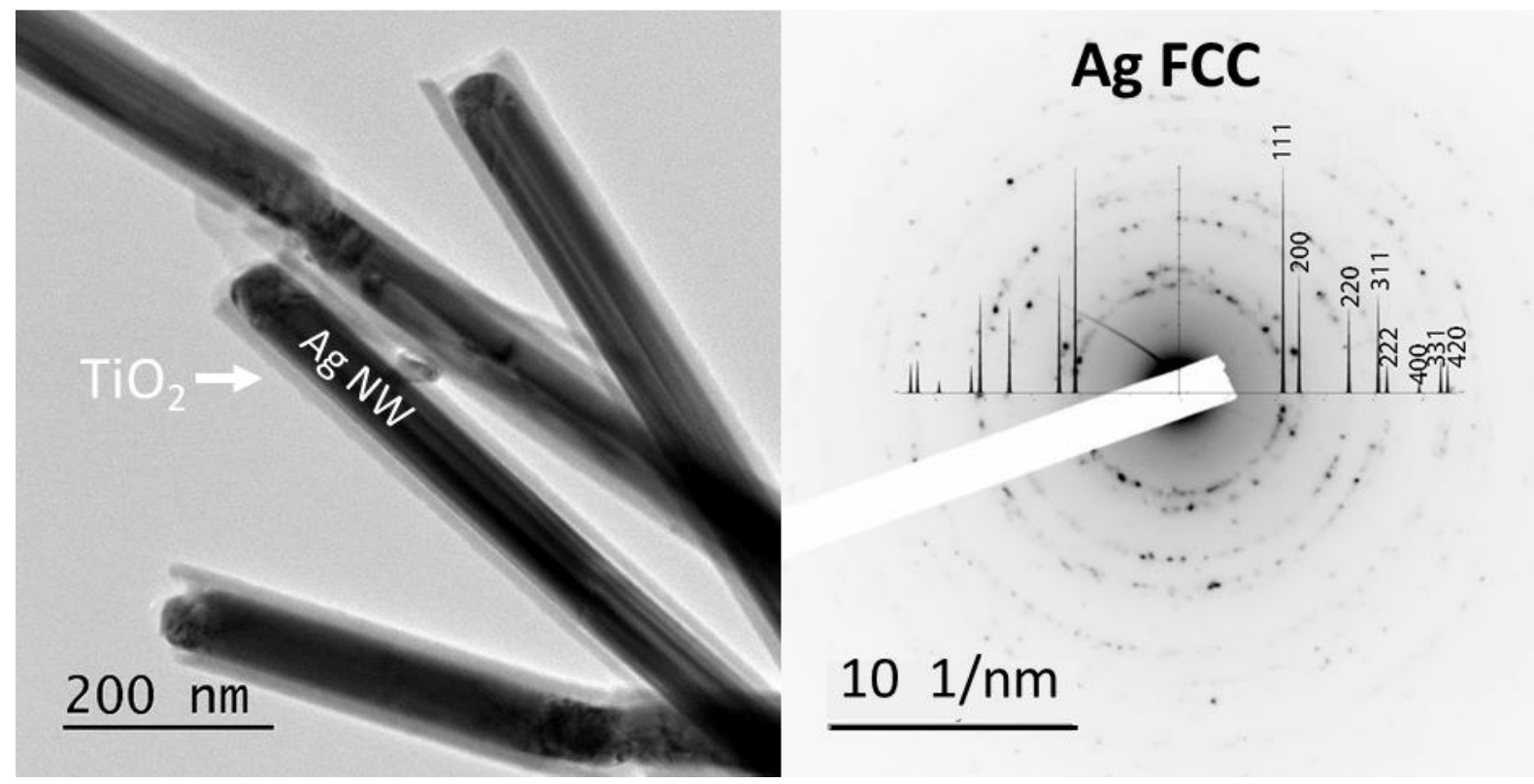

Figure S1. TEM micrographs and diffraction patterns of $\mathrm{AgNWs} / \mathrm{TiO}_{2}$ nanocomposite. The diffraction patter confirms the FCC crystalline structure of silver in the nanowires and the amorphous state of $\mathrm{TiO}_{2}$ films. 
WILEY-VCH

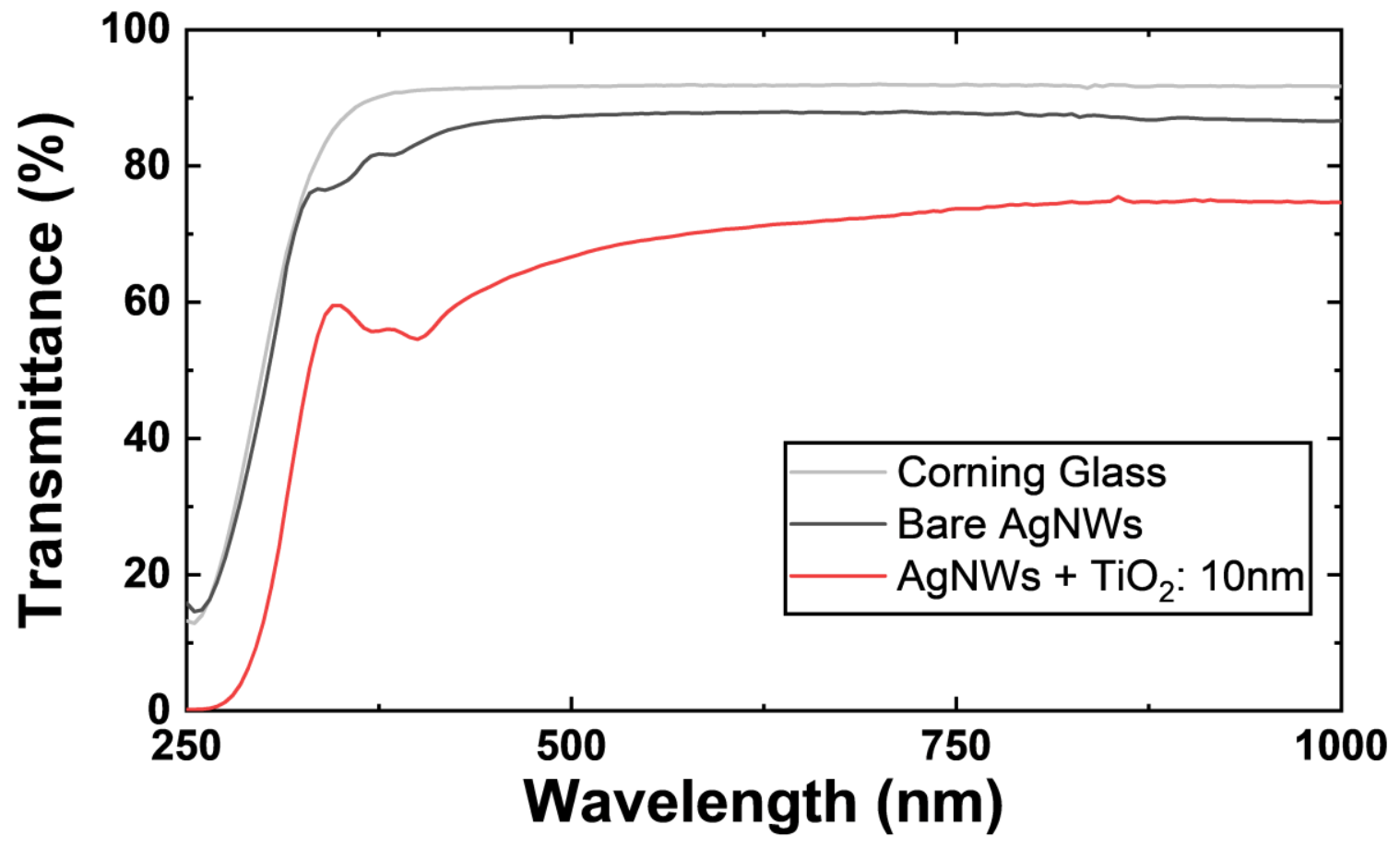

Figure S2. Transmittance of corning glass substrate, bare AgNWs and $\mathrm{AgNWs} / \mathrm{TiO}_{2}$ nanocomposite from 250 to $100 \mathrm{~nm}$. 

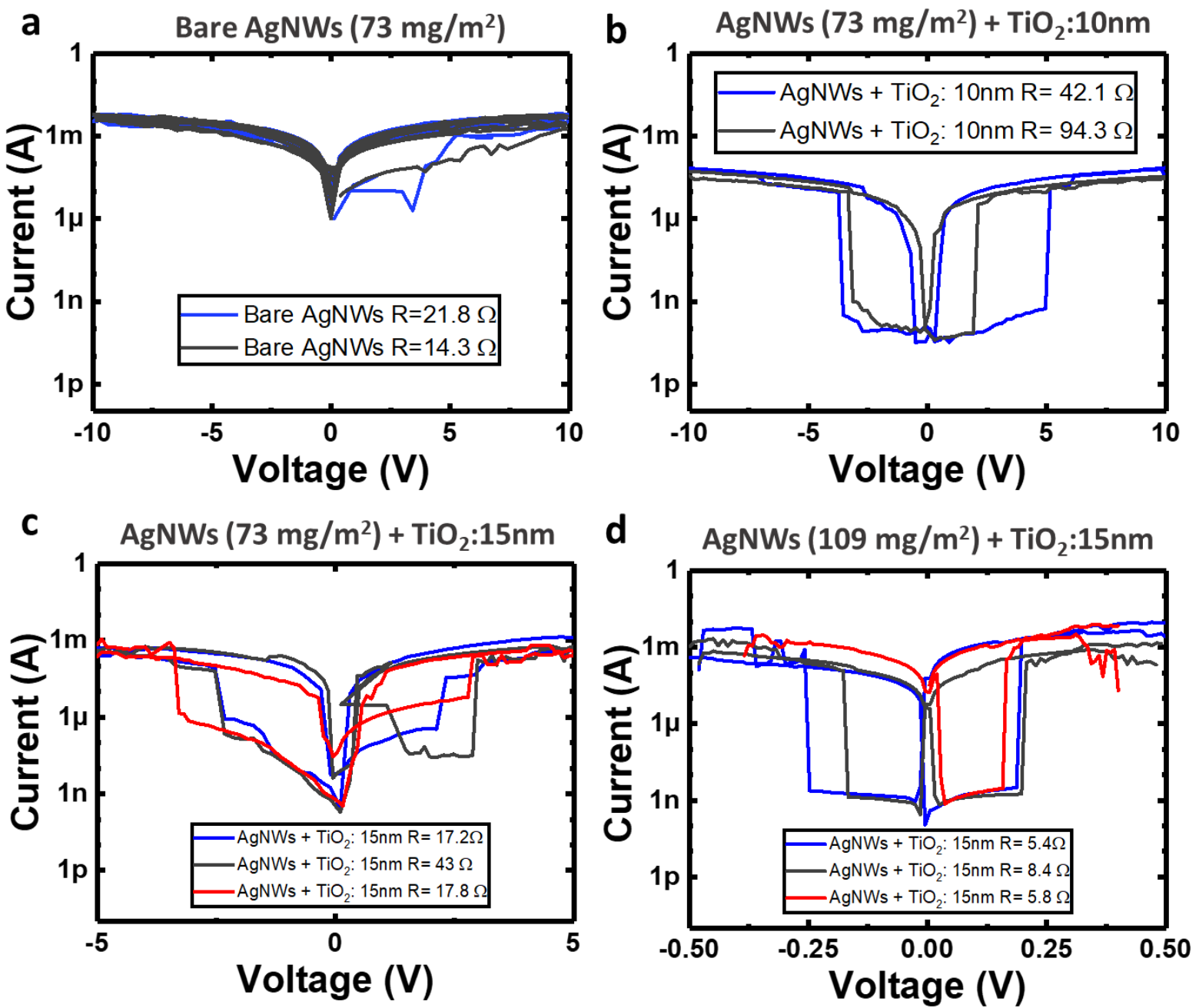

Figure S3. I-V curves for different devices of $\mathrm{AgNWs} / \mathrm{TiO}_{2}$ nanocomposites. a. 2 devices of bare AgNWs $\left(\right.$ amd $\left.=73 \mathrm{mg} / \mathrm{m}^{2}\right)$; b. 2 devices AgNWs $/ T_{i O}^{2}$ nanocomposites $\left(\right.$ amd $=73 \mathrm{mg} / \mathrm{m}^{2}$ and $\mathrm{TiO}_{2}$ thickness of $10 \mathrm{~nm}$ ); c. 3 devices $\mathrm{AgNWs} / \mathrm{TiO}_{2}$ nanocomposites (amd $=73 \mathrm{mg} / \mathrm{m}^{2}$ and $\mathrm{TiO}_{2}$ thickness of $15 \mathrm{~nm}$ ) d. 3 devices $\mathrm{AgNWs} / \mathrm{TiO}_{2}$ nanocomposites $\left(\right.$ amd $=109 \mathrm{mg} / \mathrm{m}^{2}$ and $\mathrm{TiO}_{2}$ thickness of $15 \mathrm{~nm}$ ) 


\section{WILEY-VCH}
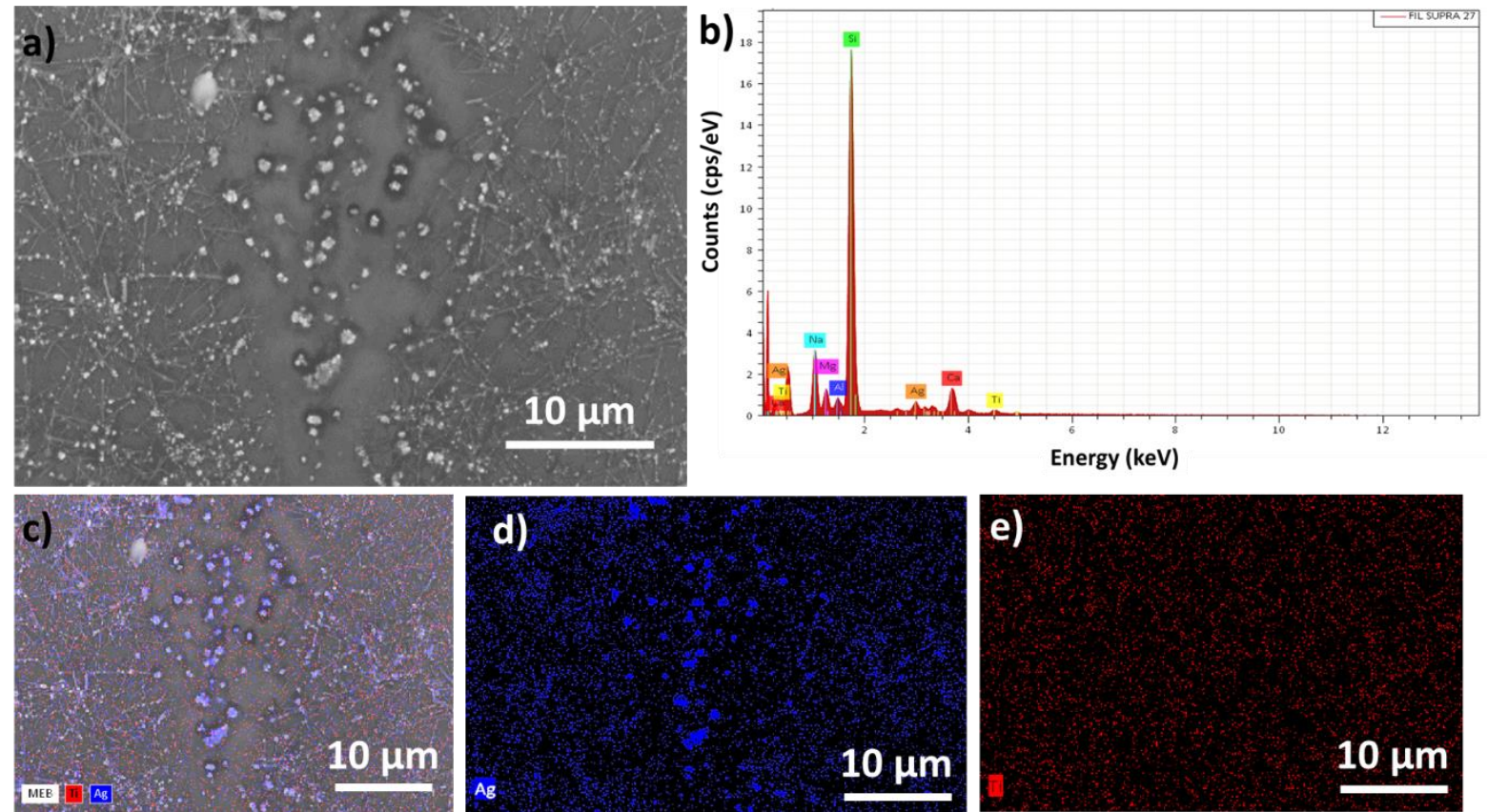

Figure S4. EDS mapping of $\mathrm{AgNWs} / \mathrm{TiO}_{2}$ nanocomposite with $15 \mathrm{~nm} \mathrm{TiO}$ layer and dense network amd $=109 \mathrm{mg} / \mathrm{m}^{2}$ a) SEM micrograph, b) EDS spectrum with different elements identified, c) SEM image overlapped with Ag and Ti EDS maps, presented individually in d) and e), respectively. 